\begin{tabular}{|c|c|}
\hline Título do capítulo & $\begin{array}{l}\text { CAPÍTULO } 12 \text { - PAPEL DOS GOVERNOS ESTADUAIS NO ENSINO } \\
\text { FUNDAMENTAL: COORDENAÇÃO INTERGOVERNAMENTAL } \\
\text { IMPORTA? }\end{array}$ \\
\hline Autores(as) & $\begin{array}{l}\text { Elaine Cristina Licio } \\
\text { Pedro Pontes }\end{array}$ \\
\hline DOI & http://dx.doi.org/10.38116/978-65-5635-005-9/cap12 \\
\hline Título do livro & $\begin{array}{l}\text { COORDENAÇÃO E RELAÇÕES INTERGOVERNAMENTAIS NAS } \\
\text { POLÍTICAS SOCIAIS BRASILEIRAS }\end{array}$ \\
\hline Organizadores(as) & Luciana Jaccoud \\
\hline Volume & - \\
\hline Série & - \\
\hline Cidade & Brasília \\
\hline Editora & Instituto de Pesquisa Econômica Aplicada (Ipea) \\
\hline Ano & 2020 \\
\hline Edição & - \\
\hline ISBN & $978-65-5635-005-9$ \\
\hline DOI & http://dx.doi.org/10.38116/978-65-5635-005-9 \\
\hline
\end{tabular}

(C) Instituto de Pesquisa Econômica Aplicada - ipea 2020

As publicações do Ipea estão disponíveis para download gratuito nos formatos PDF (todas) e EPUB (livros e periódicos). Acesse: http://www.ipea.gov.br/portal/publicacoes

As opiniões emitidas nesta publicação são de exclusiva e inteira responsabilidade dos autores, não exprimindo, necessariamente, o ponto de vista do Instituto de Pesquisa Econômica Aplicada ou do Ministério da Economia.

É permitida a reprodução deste texto e dos dados nele contidos, desde que citada a fonte. Reproduções para fins comerciais são proibidas. 



\section{PAPEL DOS GOVERNOS ESTADUAIS NO ENSINO FUNDAMENTAL: COORDENAÇÃO INTERGOVERNAMENTAL IMPORTA?}

Elaine Cristina Licio

Pedro Pontes

\section{INTRODUÇÃO}

Neste capítulo, abordamos o papel do governo estadual na educação básica, mais precisamente na gestão do ensino fundamental. A responsabilidade por esse nível de ensino é compartilhada entre entes estaduais e municipais e, por essa razão, pode configurar um fenômeno conhecido como dualidade de redes, mediante o qual escolas situadas em um território em comum - e que ofertam o mesmo nível de ensino - pertencem a redes administradas por duas esferas de governo concomitantemente. ${ }^{1}$

O necessário compartilhamento impõe a estados e municípios a definição de formas de colaboração, de modo a assegurar condições para a universalização do ensino obrigatório (art. 211, $\$ 4^{\circ}$ da Constituição Federal de 1988 - CF/1988). Essa previsão - com vistas a facilitar o processo de universalização da oferta que, à época, ainda era muito precária - resulta da combinação entre dois fatores: $i$ ) do legado histórico, uma vez que os estados eram os principais responsáveis pela oferta desse nível de ensino; e ii) da nova determinação da CF/1988, no sentido de que os entes municipais também se responsabilizassem por essa oferta - muitos dos quais, inclusive, já vinham exercendo essa atribuição, principalmente na região Nordeste. Independentemente das justificativas da sua pertinência, o fato é que regime de colaboração implica que ambos os entes estabeleçam de que maneira a oferta será garantida no seu território, definindo quais escolas e em quais localidades atenderão quais segmentos do ensino fundamental - que vai do $1^{\circ}$ ao $9^{\circ}$ ano. Ademais, embora estados e municípios possam gerir rede própria de escolas, aos primeiros também foi atribuída a função de coordenação mediante a adoção de ações supletivas e redistributivas em relação aos sistemas municipais de educação

1. É mais comum haver dualidade de redes entre escolas do ensino fundamental, ofertadas simultaneamente por redes estaduais e municipais, mas pode ocorrer também no ensino médio, no caso de ofertas estaduais e federais, dado que o governo federal tem ampliado nos anos recentes a oferta de ensino técnico e profissionalizante equivalente ao ensino médio, cuja oferta regular é de competência estadual. 
no seu território, com vistas a corrigir disparidades de acesso e garantir um padrão mínimo de qualidade de ensino (art. 75 da LDB).

Com algumas variaçôes, a dualidade de redes ${ }^{2}$ é uma característica da trajetória da política educacional brasileira mantida pela CF/1988 (Cury, 2008). Até meados do século XX, esta se caracterizava pelo fato de o governo central cuidar do ensino superior e províncias/estados, da oferta do ensino primário/fundamental (Segatto e Abrucio, 2016). A dualidade de redes no ensino fundamental assumiu suas feiçôes atuais especialmente com o processo de municipalização acentuado a partir da criação do Fundo de Manutenção e Desenvolvimento do Ensino Fundamental e de Valorização do Magistério (Fundef), em 1996, e, posteriormente, do Fundo de Manutenção e Desenvolvimento da Educação Básica e de Valorização dos Profissionais da Educação (Fundeb), em 2006. Argumentamos que esses instrumentos de coordenação, sobretudo o Fundef, inverteram o pêndulo federativo nesse segmento: se, até meados da década de 1990, os estados eram os principais ofertantes do ensino fundamental, na década seguinte, os municípios tornaram-se responsáveis pela maior parte das matrículas nesse nível de ensino (Vazquez, 2014; Araujo, 2010). Foi assim que muitos entes estaduais passaram a atuar como coadjuvantes nessa oferta, abrindo espaço para outra atuação estadual igualmente relevante: a coordenação de ambas as redes no seu território.

Estudos sugerem, no entanto, que transformar escolas estaduais em municipais não é garantia de maior qualidade da oferta educacional (Ceneviva, 2012). A melhora nos indicadores educacionais no período recente é resultado, não apenas, da municipalização em si, mas também da forma como esta vem sendo conduzida, a partir da ampliação de instrumentos de coordenação federativa operados pela União. Exemplos desses instrumentos são o Plano de Ações Articuladas (PAR), os programas federais destinados a melhorar a qualidade da educação básica e a definição de indicadores que mensurem os avanços nesse processo - como o Índice de Desenvolvimento da Educação Básica (Ideb). ${ }^{3}$

Assim, conforme demonstrado no capítulo 3, de Abramo e Licio, neste volume - que trata do papel da Uniāo na coordenação federativa da educação básica -, o período recente caracteriza-se por mudança de postura por parte da União, que tem se afastado do seu tradicional papel subsidiário na educação básica e ampliado

2. Em nossa análise, preferimos utilizar o termo dualidade à duplicidade de redes, como parte da literatura adota eventualmente. Embora ambos os termos possam funcionar como sinônimos, no sentido de identificar aquilo que tem duas substâncias/naturezas, duplicidade pode trazer a ideia de falsidade ou fingimento, razão pela qual entendemos que o termo dualidade, por ser mais neutro, caracteriza melhor nosso objeto.

3. 0 Índice de Desenvolvimento da Educação Básica (Ideb) foi criado em 2007, pelo Instituto Nacional de Estudos e Pesquisas Educacionais Anísio Teixeira (Inep), e formulado para medir a qualidade do aprendizado nacional e estabelecer metas para a melhoria do ensino. 0 uso do Ideb é obrigatório para as escolas públicas, mas facultativo para as escolas privadas, sendo calculado a partir de dois componentes: a taxa de rendimento escolar (aprovação) e as médias de desempenho nos exames aplicados pelo Inep. Os índices de aprovação são obtidos a partir do Censo Escolar, realizado anualmente. 
sua participação e responsabilidade nos arranjos e instrumentos de coordenação. Todavia, embora todo esse processo tenha produzido uma melhoria nos resultados educacionais, isso não se distribuiu de maneira uniforme em todo o território nacional. Ainda há diferenças significativas nas condições de oferta e resultados, tanto em termos regionais quanto entre escolas em um mesmo território ${ }^{4}$ (Torres et al., 2006; Castro, 2009; Arretche, Fusaro e Gomes, 2012; Inep, s.d.).

Tal situação tem demandado a ampliação da coordenação da atuação dos entes federativos, mediante a adoção de arranjos institucionais que viabilizem a cooperação (art. 23, X) e o regime de colaboração (art. 211), com vistas a assegurar a equalização de oportunidades educacionais e a garantia de um padrão mínimo de qualidade (art. 211, $\mathbb{S} 1^{\circ}$ da CF/1988). É nesse contexto que se propóe a criação de um sistema nacional de educação que articule os sistemas dos três níveis de governo, de modo a alcançarem as metas do Plano Nacional de Educação (PNE), como forma de assegurar o direito à educação. ${ }^{5}$ Entretanto, considerando-se que a assistência técnica e financeira disponibilizada aos entes subnacionais por meio de programas federais do Ministério da Educação (MEC) ${ }^{6}$ tende a afetar de forma mais homogênea os resultados da política, entendemos que o que pode fazer diferença é a atuação do nível estadual, por meio de estratégias próprias de coordenação das redes estaduais e municipais no seu território (Gomes, 2009; Abrucio, 2010; Segatto, 2015; Segatto e Abrucio, 2016). Nesse sentido, Segatto (2015) pontua que, enquanto o governo federal adota mecanismos de coordenação desde 1996, a cooperação entre estados e municípios é bem mais recente, ainda em desenvolvimento.

Via de regra, os estudos que se dedicam a analisar a atuação dos governos estaduais na política de educação enfocam seu papel enquanto gestor de rede de escolas (Fillipim e Abrucio, 2010; Fracalanza, 1999; Sanfelice, 2010; Souza e Arcas, 2010). Mais recentemente, alguns estudos passaram a destacar seu papel enquanto coordenador de redes estaduais e municipais no seu território (Gomes, 2009; Segatto, 2015; Segatto e Abrucio, 2016; Segatto, 2017). Em pesquisa sobre o papel dos estados na política educacional, Segatto (2015) identificou diferentes modelos de relacionamento estadual com os municípios, os quais variam da independência na gestão das respectivas redes até situações de efetiva coordenação estadual, no sentido de induzir a cooperação entre os entes. A autora avalia que, apesar de a maioria das relaçóes entre os governos subnacionais na educação ser

4. Castro (2009), por exemplo, mostra que em 2009 a escolaridade média da região Sudeste era de oito anos, enquanto na região Nordeste era de apenas seis anos. A população rural estudava, em média, quatro anos a menos que a urbana cuja média era de 8,5 anos de estudo -, enquanto negros estudavam, em média, dois anos a menos que os brancos. 5. Ver capítulo 10, de Licio e Pontes, neste volume.

6. Executados pelo Fundo Nacional de Educação (FNDE), programas do Ministério da Educação (MEC) apoiam estados, municípios e respectivas escolas em diversas áreas, como fornecimento de livro didático, transporte e merenda escolar, qualificação de professores, educação integral, construção e reforma de equipamentos etc. 
pouco institucionalizada, há uma tendência de expansão e fortalecimento da cooperação entre ambos os níveis de governo (Segatto, 2015; Codes et al, 2017).

Realizamos aqui uma análise mais abrangente da atuação dos governos estaduais, investigando de que maneira têm se apropriado do seu duplo papel na coordenação e oferta do ensino fundamental e como isso impacta os resultados da política. Assim, abordamos a interação entre o modelo de atuação dos estados e a melhoria no desempenho educacional - medido pelo Ideb - no decênio 2005-2015.

Partimos do pressuposto de que a opção política pela maior ou menor descentralização das matrículas no ensino fundamental delimita o espaço para ações de coordenação estadual, de modo que quanto maior a municipalização, maior a relevância das açóes que busquem evitar sobreposiçóes, lacunas e desigualdades de diversas ordens entre os diversos sistemas de ensino que operam no mesmo território. Assim, procuramos associar o uso de estratégias de coordenação com melhores resultados na política, pois é com vistas a ampliar sua qualidade que as iniciativas de coordenação são mobilizadas. Para tanto, a pesquisa baseou-se em levantamento bibliográfico, pesquisas e dados sobre a oferta e os resultados relativos à política de educação.

O trabalho está dividido em três seçóes, além desta introdução e das consideraçôes finais. Na segunda seção, verificamos como os governos estaduais têm se organizado junto aos respectivos municípios para oferta do ensino fundamental. $\mathrm{Na}$ terceira seção, analisamos o fenômeno da dualidade de redes nos anos finais do ensino fundamental e sua associação aos resultados educacionais medidos pelo Ideb. Na quarta seçấo, identificamos os perfis de atuação dos governos estaduais na oferta desse segmento de ensino e os principais desafios de coordenação para ampliar a qualidade da oferta educacional. Nas consideraçóes finais, sintetizamos os achados da pesquisa.

\section{PAPEL DOS ESTADOS NO ENSINO FUNDAMENTAL: DA GESTÃO DA PRÓPRIA REDE À COORDENAÇÃO FEDERATIVA NO SEU TERRITÓRIO}

Nesta seção, analisamos como os governos estaduais têm se organizado junto aos respectivos municípios para oferta do ensino fundamental, tendo em vista seu duplo papel: de gestão da própria rede de escolas e de coordenação federativa.

Antes da CF/1988, a educação básica estava sob a responsabilidade dos governos estaduais e do Distrito Federal (DF), cabendo à União atuar em caráter supletivo (art. 169 da CF/1967). Os municípios não tinham autonomia para manter sistemas próprios de ensino, de forma que aqueles que possuíam escolas eram supervisionados pelos governos estaduais. A CF/1988 incluiu os municípios no rol 
dos entes federativos, e a estes conferiu a responsabilidade pelo ensino fundamental (art. $211, \mathbb{\$} 2^{\circ}$ ), permitindo a criação de sistemas municipais autônomos. Todavia, o texto original da Carta Magna não delimitou explicitamente o papel dos estados no ensino fundamental, deixando vago o escopo da sua atuação nesse segmento da política. Foi somente com a Emenda Constitucional (EC) no 14/1996 que se detalharam as competências desses entes, atribuindo-lhes a responsabilidade pelos níveis fundamental e médio de ensino. Naquele ano, a Lei de Diretrizes e Bases determinou a atribuiçáo do nível estadual de governo enquanto coordenador das respectivas redes estadual e municipais, por meio de açóes supletivas e redistributivas no seu território (art. 75 da LDB). Todavia, nem a CF/1988, nem a LDB e nem o MEC definiram como essa coordenação poderia ser operada (Segatto, 2017).

O Fundef, também objeto da EC no 14/1996, instituiu um modelo de coordenação financeira que redistribuiu os recursos estaduais e municipais destinados à educação, agregados de suplementação por parte da União. Sua operação baseava-se na definição de um valor mínimo de gasto por aluno em cada Unidade Federativa (UF), distribuído segundo o número de alunos matriculados em cada rede - estadual ou municipal. Ao ser repassado para o ente que efetivamente provia a vaga na escola, o Fundef promoveu a diminuição das desigualdades de gasto por aluno no nível intraestadual e funcionou como incentivo financeiro aos municípios que, na maior parte dos casos, passaram a contar com recursos novos para atender à demanda por escolas. Essa mesma lógica de compartilhamento de recursos estaduais e municipais - suplementada pela União e redistribuída de acordo com as matrículas efetivadas por cada ente - foi adotada pelo Fundeb a partir de 2006, cujo financiamento se estendeu também à educação infantil e ao ensino médio.

Longe de favorecer o isolamento, a autonomia conferida aos entes subnacionais na política educacional - instrumentalizada pela garantia de valor mínimo por aluno em nível nacional e intraestadual - implica que cada um decida de que maneira agirá conjuntamente, nos casos em que isso seja necessário para assegurar a oferta adequada da política. Essa distribuição de competências pressupóe algum grau de coordenação entre redes estaduais e municipais de ensino, não apenas para a oferta do nível fundamental, mas também para articular conteúdos que permitam aos alunos transitar entre essas redes, de modo a seguir o percurso educacional obrigatório, que, desde a EC no 59/2009, vai do ensino infantil ao médio.

Na próxima subseção, analisamos como estados e municípios têm se organizado no período recente, considerando-se que a competência compartilhada para oferta do ensino fundamental permite a conformação de diferentes arranjos institucionais para esse fim. 


\subsection{A oferta do ensino fundamental pelas redes estaduais e municipais}

A análise da movimentação das matrículas no ensino fundamental evidenciada no gráfico 1 revela variaçóes relevantes. Embora a rede particular tenha avançado relativamente nas duas últimas décadas, é no âmbito dos entes subnacionais que verificamos uma inflexáo. Os municípios passaram a se apropriar de fatia cada vez maior das matrículas, alterando sua participação de $32,11 \%$ para $56,27 \%$ do total apurado no período, acompanhado de importante redução das ofertas estaduais, que, inversamente, saíram do patamar de 56,56\% para 27,28\% das matrículas do ensino fundamental.

GRÁFICO 1

Matrículas no ensino fundamental por esfera administrativa ${ }^{7}$ - Brasil (1995-2015) (Em \%)

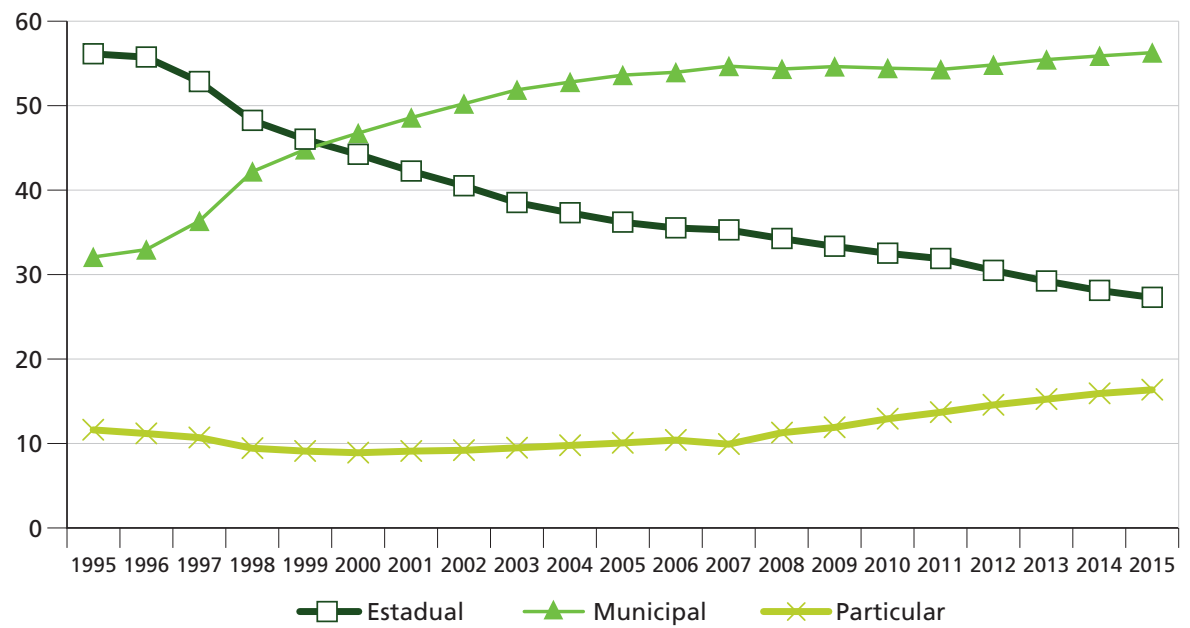

Fonte: Inep (2015)

Elaboração dos autores.

Contudo, esse processo não foi uniforme. Em alguns estados, as matrículas foram mais municipalizadas que em outros. Isso fica nítido quando separamos a análise nos dois ciclos do ensino fundamental (anos iniciais e finais). ${ }^{8}$ A figura 1 mostra que, em termos nacionais, os anos iniciais vêm sendo oferecidos, principalmente, pelas redes municipais, enquanto nos anos finais a distribuição é mais equilibrada, com maior municipalização nas regiōes Norte e Nordeste.

7. Há em todas as unidades federativas (UFs) escolas federais que ofertam ensino fundamental, mas seu percentual de matrículas é muito inferior às demais esferas (menor que 1\%), razão pela qual optamos não exibi-lo no gráfico. 8. Até 2006, o ensino fundamental era de oito anos, para a faixa etária de 7 a 14 anos. A Lei no 11.274/2006 estendeu sua duração para nove anos, ofertado para a faixa etária de 6 a 14 anos. 0 ensino fundamental divide-se em: anos iniciais duração de cinco anos -, para a faixa etária de 6 a 10 anos, correspondendo ao período que vai da 10 ao 50 ano; e anos finais - duração de quatro anos -, para a faixa etária de 11 a 14 anos, que abrange o período que vai do 6 a 9ำ ano. 


\section{FIGURA 1}

Mapa com percentual de matrículas municipais (2015)

$1 \mathrm{~A}$ - Anos iniciais

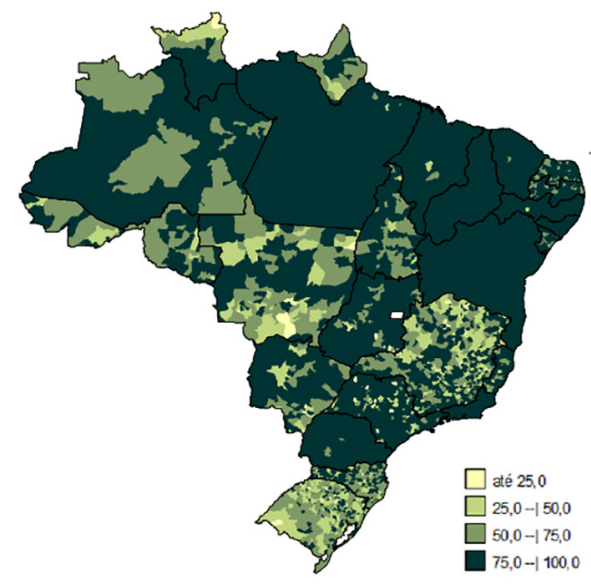

$1 \mathrm{~B}$ - Anos finais

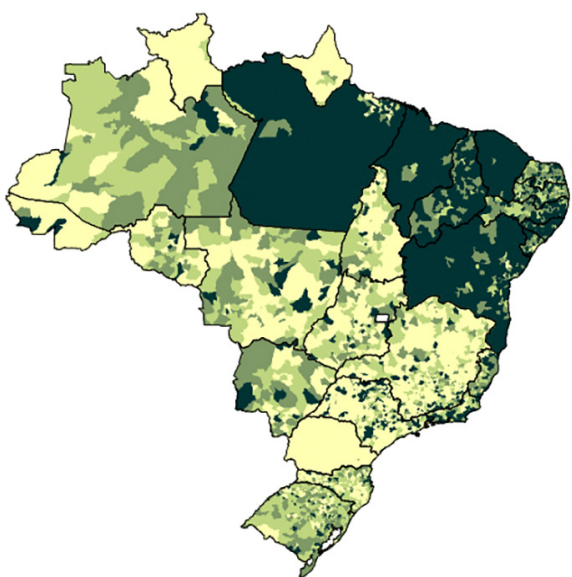

Fonte: Inep (2015).

Elaboração dos autores.

Obs.: Figura reproduzida em baixa resolução e cujos leiaute e textos não puderam ser padronizados e revisados em virtude das condições técnicas dos originais (nota do Editorial).

O gráfico 2 mostra a extensão do processo de municipalização do ensino fundamental nos anos iniciais em cada UF, para o qual os municípios figuram como responsáveis pela maior parte das matrículas - ainda que, em alguns casos, as matrículas estaduais sejam importantes, com incidência maior que 30\% (Acre, Rio Grande do Sul, Amapá, Minas Gerais, Mato Grosso e Rondônia).

Em 2015, mais de 80\% das matrículas nos anos iniciais do ensino fundamental eram municipais. Esse processo avançou substancialmente após o Fundef (1996) e continuou após o Fundeb (2006), sendo significativo em todas as UFs. Na visão de Sandra Gomes (2009), porém, a variação entre os graus de municipalização nos estados não foi resultado apenas do interesse dos municípios em aumentar a provisão de serviços, tendo sido afetada também pelo papel indutor dos governos estaduais, como a disponibliização de programas próprios de descentralização. 
GRÁFICO 2

Evolução de matrículas municipais: anos iniciais (Em \%)

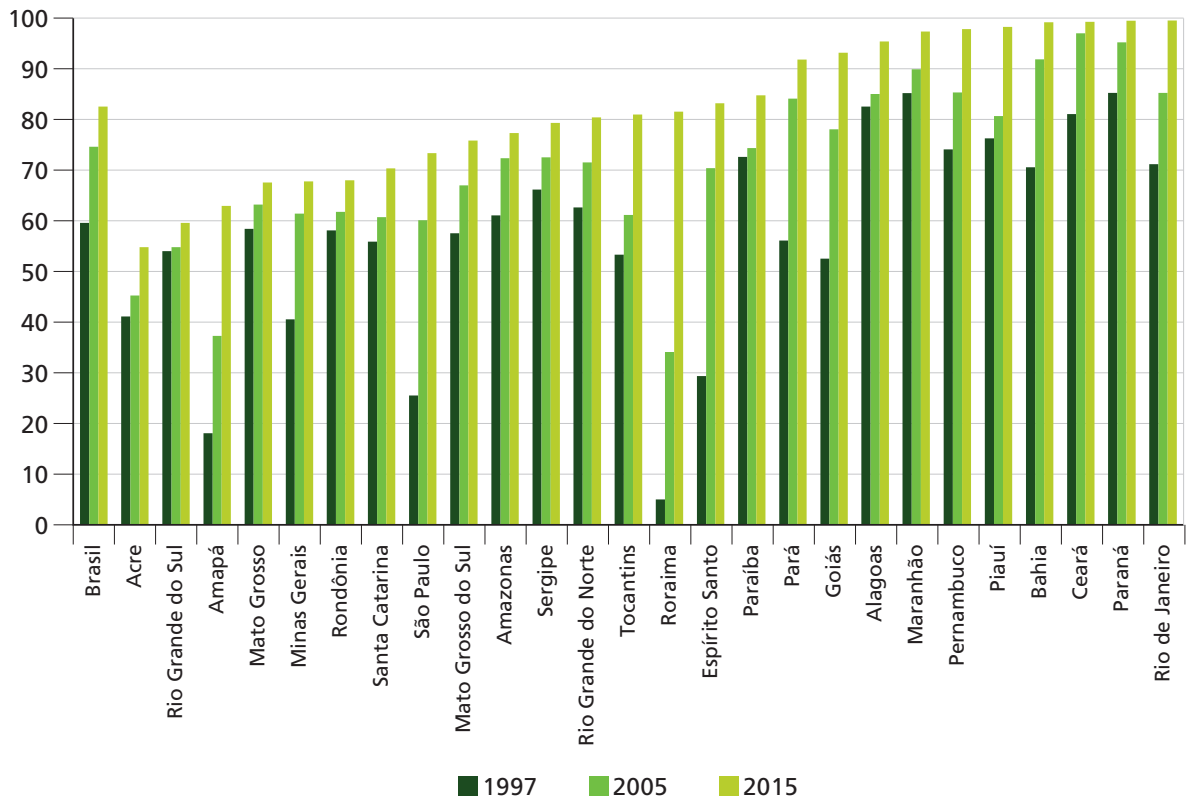

Fonte: Instituto Nacional de Estudos e Pesquisas Educacionais Anísio Teixeira (Inep) do MEC.

Elaboração: Inep (2015).

Obs.: Iniciamos a série histórica em 1997, pois foi só a partir de então que os dados sobre matrículas divulgados pelo MEC passaram a agregar a informação para os dois ciclos do ensino fundamental analisados (anos iniciais e anos finais).

Nos anos finais do ensino fundamental, a distribuição de matrículas entre os entes é mais equilibrada. É justamente nessa modalidade de ensino que verificamos, no âmbito estadual, a maior diversidade de arranjos de oferta. Embora boa parte dos estados tenha avançado na municipalização desde o Fundef, o gráfico 3 revela que, após o advento do Fundeb em 2006, alguns estados retrocederam, chegando a "desmunicipalizar" ou "reestadualizar" matrículas no período (Paraná, Roraima, Amapá, Acre, Rondônia e Mato Grosso).

Assim, os anos finais do ensino fundamental constituem o nível de ensino em que a dualidade de redes - mediante a coexistência de redes estaduais e municipais no mesmo território - é mais proeminente, e, portanto, é nesse âmbito que a ação de coordenação estadual pode ser mais relevante, no sentido de reduzir disparidades de acesso e garantir padrão mínimo de qualidade da oferta no seu território, independentemente do ente responsável pela sua oferta. 
GRÁFICO 3

Evolução de matrículas municipais: anos finais

(Em \%)

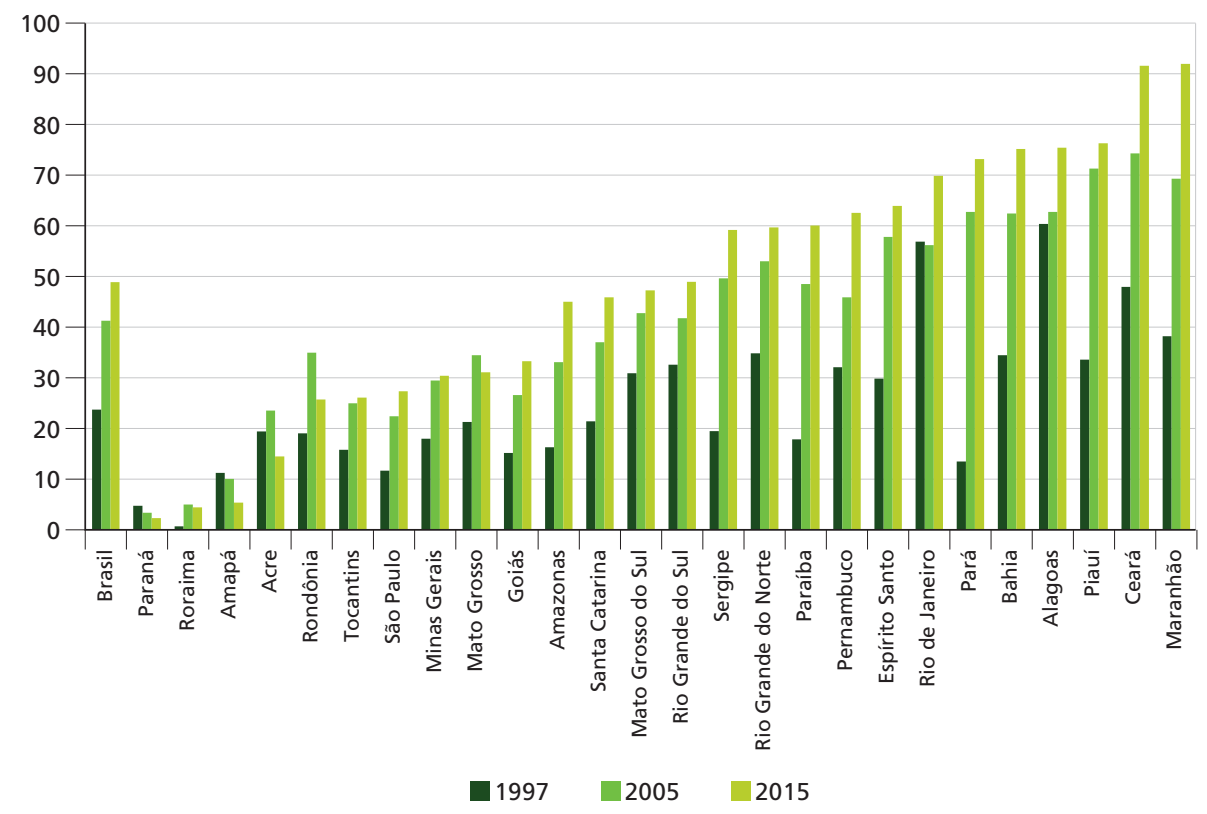

Fonte: Inep/MEC (2015).

Elaboração dos autores.

Outra forma de analisar essas mudanças na organização federativa da política de educação é por meio do seu financiamento. Nesse sentido, Castro (2014) mostra que o nível municipal de governo foi o que mais ampliou seus gastos na educação a partir do Fundef/Fundeb. Isso foi reflexo não apenas do aumento relativo do gasto no ensino fundamental, mas também da intensa municipalização desse nível de ensino, sobretudo no que se refere à oferta do seu primeiro ciclo (anos iniciais - $1^{\circ}$ ao $5^{\circ}$ ano). Esse segundo aspecto, principalmente, fez com que grande parcela dos recursos de origem estadual fosse executada pelos municípios via Fundef/Fundeb, os quais passaram a ser seus principais ofertantes.

Dessa forma, houve um declínio no percentual de recursos executados pelos estados no período, embora "dizer que a participação dos estados tem diminuído não significa afirmar que os recursos de origem estaduais destinados à educaçấo estáo decrescendo, em termos absolutos" (Castro, 2014, p. 191). Na visáo do autor, o que tem decrescido a partir da municipalização das matrículas não é o financiamento estadual - fixado pelo Fundeb -, mas, sim, a própria oferta estadual do ensino fundamental, como evidenciamos anteriormente no gráfico 1. Assim, embora tenham deixado de protagonizar a oferta do ensino fundamental a partir do Fundef/Fundeb, os entes estaduais permanecem como o nível de governo que 
mais contribui financeiramente para a educação básica. Nesse sentido, lembramos que - além das respectivas quotas-parte do Fundo de Participação dos Estados (FPE), do Fundo de Participação dos Municípios (FPM) e de impostos federais por parte de estados e municípios - o Fundeb é financiado majoritariamente por impostos estaduais, sem incluir impostos municipais. ${ }^{9}$

Segatto (2017) argumenta que a coordenação estado-municípios pode influenciar as políticas municipais de diferentes modos, como, por exemplo, possibilitar maior equalização em recursos e capacidades administrativas, evitar sobreposições e lacunas na provisão dos serviços educacionais, melhorar a implementação de políticas nacionais etc.

Nesse contexto, consideramos que analisar as implicaçóes desse novo arranjo federativo de oferta do ensino fundamental, sob a ótica da coordenação federativa, justifica-se por vários aspectos. Primeiro porque a garantia de um valor mínimo de gasto por aluno pelo Fundeb não seria suficiente para reduzir desigualdades entre as redes de escolas. Segundo, dado que os instrumentos de coordenação a cargo da União para ampliar a qualidade da educação - em especial, os programas federais de apoio a estados e municípios para gestão da educação básica - estão "disponíveis" a todos os entes federativos, a coordenação no nível regional da política é que poderá fazer mais diferença, no sentido de reduzir as desigualdades intraestaduais. Em terceiro lugar, a coordenação estadual mostra-se ainda mais essencial se considerarmos que pelo menos $30 \%$ dos alunos que concluem os anos iniciais em escolas municipais, necessariamente, migram para escolas estaduais nos anos finais, ${ }^{10}$ demandando a articulação de conteúdos e metodologias de ensino de ambos os ciclos, para que as crianças não enfrentem problemas nessa transição.

\subsection{Coordenação estadual na oferta do ensino fundamental}

Ao tratar das políticas públicas, Souza (2018) define coordenação como processo de organização de atividades, com o objetivo de alcançar consenso entre indivíduos/ organizaçóes para o atingimento dos objetivos de um grupo. Nesses termos, coordenar implica o alinhamento da atuaçáo de diversos atores em torno de um propósito, que, no caso em tela, consubstancia-se na garantia do acesso ao direito à educaçáo.

Souza (2018) pondera que o modelo brasileiro de coordenação federativa nas políticas sociais privilegia a relação entre o governo federal e o municipal, com escassa

9. 0 Fundo de Manutenção e Desenvolvimento da Educação Básica e de Valorização dos Profissionais da Educação (Fundeb) é composto por 20\% das seguintes fontes de arrecadação: Imposto sobre Operações relativas à Circulação de Mercadorias e Prestação de Serviços de Transporte Interestadual e Intermunicipal e de Comunicação (ICMS); Fundo de Participação dos Estados (FPE); Fundo de Participação dos Municípios (FPM); Imposto sobre Produtos Industrializados (IPI); Imposto sobre a Transmissão Causa Mortis e Doação (ITCMD); Imposto Territorial Rural (ITR); e desoneração de exportações, de que trata a Lei Complementar (LC) № $87 / 96$ (Lei Kandir).

10. 0 raciocínio é simples. Se $83 \%$ das matrículas nos anos iniciais e, apenas, $49 \%$ das matrículas nos anos finais são municipais, significa que, pelo menos, $30 \%$ dos que concluem os anos iniciais terão de mudar de rede para seguir nos estudos finais - caso permaneçam em escola pública. 
participação estadual. ${ }^{11}$ Acrescenta que alguns estudos apontam falhas ou omissões no papel de coordenação do estado, até mesmo quando o desenho da política lhe atribui, explicitamente, essa responsabilidade. Esse é o caso da pesquisa de Segatto e Abrucio (2016), os quais analisaram a atuação dos governos estaduais junto aos municípios na área da educação. Os autores reconhecem a importância do papel coordenador estadual não somente quando este opta por municipalizar as matrículas, mas também quando possui rede própria de ensino. Constatam ainda que, embora a articulaçáo federal com os estados tenha avançado em termos financeiros com o Fundef/Fundeb, esta ainda é incipiente sob os aspectos políticos e gerenciais, dado que são poucos os programas federais que exigem que os governos estaduais os coordenem regionalmente. Ademais, avaliam que a função coordenadora dos estados em âmbito regional é fundamental, mas não deve, necessariamente, ser homogênea para produzir melhores resultados educacionais. Nesse sentido, relatam que alguns estados com resultados parecidos no Ideb adotam graus de cooperação distintos: São Paulo, por exemplo, não possui coordenação tão ativa, enquanto o Ceará apresenta uma lógica mais permanente, institucionalizada e sistêmica de coordenação federativa (Segatto e Abrucio, 2016).

Outro aspecto destacado pelos autores, que corrobora a visão de Souza (2018), é que as relaçóes verticais que o governo federal estabelece com os municípios são mais uniformes do que aquelas entre os estados e o ente local. Enquanto as regulamentaçóes nacionais, a redistribuição de recursos e os programas federais seriam válidos para todos os municípios, a cooperação entre estados e municípios varia no seu conteúdo e sua institucionalização, inclusive entre municípios em um mesmo estado.

Nesse contexto, Segatto (2015) desenvolveu uma tipologia de graus de coordenação estadual, a partir de entrevistas com os responsáveis pela relação com os municípios nas secretarias estaduais de educação. ${ }^{12}$ As formas e as possibilidades de interação entre ambos os entes encontradas na pesquisa foram diversas:

formação inicial e/ou continuada, redistribuição de recursos, distribuição de materiais didáticos, permuta de burocratas e cessão de prédios públicos (geralmente atrelados aos processos de municipalizaçáo), matrícula conjunta, convênios, especialmente, relacionados à merenda e ao transporte escolar, assessoria técnica e pedagógica e negociação federativa (Segatto, 2015, p. 81).

Apropriamo-nos e ajustamos a tipologia criada por Segatto (2015), com o objetivo de categorizar os diferentes graus de coordenação observados na política educacional em âmbito estadual. Foram feitas duas mudanças quanto à categorizaçáo original: primeiro, incluímos o Mato Grosso do Sul no rol dos estados com maior

11. Arretche, Vazquez e Gomes (2012), inclusive, lembram que, com variações, esse tipo de relação já existia desde a Primeira República, mediante a qual o governo federal buscava apoiar diretamente os municípios justamente para anular os poderes estaduais sobre estes.

12. Segundo a autora, os dados foram coletados em 2013, por meio de questionário sobre a existência de ações ou programas de cooperação e arenas de negociação entre estados e municípios, a criação de órgãos específicos nas secretarias estaduais de educação responsáveis por essa relação e a oferta de programas de municipalização nos estados (Segatto, 2015). 
coordenação estadual. ${ }^{13} \mathrm{O}$ segundo ajuste deve-se ao reposicionamento do Rio Grande do Sul como um estado com menor grau de coordenação, em que ocorrem apenas açóes conjuntas. ${ }^{14}$

O quadro mostra que, de maneira geral, as relações entre os entes são bastante heterogêneas, variando em grau de institucionalização e redistribuição de recursos (financeiros, materiais e humanos). Os modelos podem ser hierárquicos, negociados ou independentes, pouco ou muito institucionalizados, formais e informais. Os grupos também são heterogêneos em sua composição, integrados por estados de diferentes regiôes e níveis socioeconômicos, e mostrando que a disposição em coordenar não, necessariamente, está relacionada com maior disponibilidade de recursos.

Não se deve perder de vista que a função coordenadora dos estados se justifica enquanto meio para reduzir as disparidades regionais e garantir padrão mínimo de qualidade do ensino. Na próxima seção, analisamos, a partir da tipologia do quadro 1 , como tem se relacionado com os resultados educacionais no período recente.

QUADRO 1

Tipologia segundo os graus de coordenação federativa dos governos estaduais (ajustada)

\begin{tabular}{|c|c|c|}
\hline $\begin{array}{l}\text { Grau de coordenação } \\
\text { estadual }\end{array}$ & Características & UFs \\
\hline $\begin{array}{l}1 \text { - Políticas } \\
\text { independentes }\end{array}$ & $\begin{array}{l}\text { Pouca ou nenhuma cooperação. Ocorrência de conflito/ } \\
\text { competição entre os entes. }\end{array}$ & $\begin{array}{l}\text { Rondônia, Roraima, Pará, Amapá, } \\
\text { Maranhão, Rio Grande do Norte, Rio de } \\
\text { Janeiro e Santa Catarina. }\end{array}$ \\
\hline 2 - Ações conjuntas & $\begin{array}{l}\text { Cooperação fraca, pouco institucionalizada e, em alguns } \\
\text { casos, não intencional. Não envolve redistribuição de } \\
\text { recursos. }\end{array}$ & $\begin{array}{l}\text { Amazonas, Alagoas, Espírito Santo, São } \\
\text { Paulo, Paraná e Rio Grande do Sul. }\end{array}$ \\
\hline $\begin{array}{l}3 \text { - Programas } \\
\text { conjuntos }\end{array}$ & $\begin{array}{l}\text { Cooperação institucionalizada entre estados e municípios. } \\
\text { Redistribuição de recursos materiais e humanos. } \\
\text { Cooperação resulta de negociação contínua entre } \\
\text { estados e municípios, o que leva à variação no grau de } \\
\text { institucionalização e em seu conteúdo. }\end{array}$ & $\begin{array}{l}\text { Acre, Tocantins, Sergipe, Piauí, } \\
\text { Pernambuco, Bahia, Minas Gerais, Mato } \\
\text { Grosso e Goiás. }\end{array}$ \\
\hline $\begin{array}{l}4 \text { - Coordenação } \\
\text { estadual' }\end{array}$ & $\begin{array}{l}\text { Cooperação institucionalizada entre os entes, em caráter } \\
\text { mais verticalizado. Estado induz fortemente a cooperação. } \\
\text { Envolve redistribuição de recursos financeiros, materiais e } \\
\text { humanos. }\end{array}$ & Ceará, Paraíba e Mato Grosso do Sul. \\
\hline
\end{tabular}

Fonte: Segatto (2015) e Segatto e Abrucio (2016).

Elaboração dos autores.

Nota: ' Conquanto os estados, nessa categoria, apresentem mecanismos desenvolvidos de coordenação junto aos municípios, é necessário destacar que o Ceará apresenta um modelo particular de coordenação estadual, com medidas como premiação financeira por alcance de metas.

13. Isso se justifica porque a autora fez a mesma mudança em trabalho posterior, colocando Mato Grosso do Sul junto ao Ceará na categoria de estados com maior grau de coordenação federativa (Segatto e Abrucio, 2016).

14. A autora justifica a criação da categoria resolução de conflitos para o Rio Grande do Sul, por ser este o único estado com duas arenas institucionalizadas para a negociação federativa junto aos municípios. Todavia, a partir de entrevistas realizadas com gestores da educação no Rio Grande do Sul em 2016, relatos de gestores e conselheiros estaduais dão conta de que tais arenas até chegaram a tratar de temas relevantes na articulação estado-municípios - como transporte escolar e financiamento -, mas que, como tomavam muito tempo e eram tratados também em outros espaços, foram aos poucos deixando de ser abordados. Há relatos ainda, no que se refere ao grupo ligado ao Conselho Estadual de Educação, de certo distanciamento entre o que era acordado nas reuniões - com representantes da Secretaria Estadual de Educação, da União Nacional dos Dirigentes Municipais de Educação (Undime) e da União Nacional dos Conselhos Municipais de Educação (Uncme) - e o que era efetivamente implementado. 


\section{EXPLORANDO POSSÍVEIS CONEXÕES ENTRE COORDENAÇÃO ESTADUAL E EVOLUÇÃO DO IDEB NA OFERTA DO ENSINO FUNDAMENTAL}

Sendo um dos principais fatores do desenvolvimento humano, a educação de qualidade pressupóe que escolas em territórios mais vulneráveis devem contribuir para reverter - no médio e longo prazo - as profundas desigualdades educacionais que no Brasil se manifestam entre ricos e pobres, entre a população rural e urbana, e também entre regióes do país. Aliás, esse é um dos objetivos da coordenação federativa em matéria de educação: reduzir desigualdades diante dos preceitos constitucionais de equalização das oportunidades educacionais e garantia de padrão mínimo de qualidade. $\mathrm{O}$ que deve ser conduzido por meio da cooperação e colaboração entre os entes federativos.

A partir dessas premissas, buscamos analisar, nesta seção, como se relacionam o grau de coordenação federativa adotado pelos governos estaduais e a evolução dos resultados educacionais para os anos finais do ensino fundamental, no que diz respeito às escolas públicas do seu território. Como indicador de qualidade, adotamos o Ideb, apurado a cada dois anos pelo Instituto Nacional de Estudos e Pesquisas Educacionais Anísio Teixeira (Inep) desde 2005. Sua escolha como fator de mensuração da qualidade da oferta ${ }^{15}$ justifica-se na medida em que busca captar o efetivo aprendizado pelos alunos - finalidade precípua da educação -, além de estabelecer metas para a melhoria do ensino. Ademais, após mais de uma década de apuração, consideramos que hoje o Ideb conta com ampla adesão dos atores envolvidos na gestão da educação básica, de modo a pautar as decisóes sobre a gestão da política nos três níveis de governo.

Dados do Inep indicam que o Ideb das escolas públicas relativas aos anos iniciais do ensino fundamental tem avançado a contento, de modo que apenas três entes federativos não alcançaram as respectivas metas em 2015 (Amapá, Sergipe e Rio de Janeiro) (Inep, [s.d.]). Para nossa análise, entretanto, interessa conhecer o desempenho das escolas públicas nos anos finais do ensino fundamental que, como vimos anteriormente, apresenta maior heterogeneidade de arranjos de oferta simultânea por redes estaduais e municipais. O gráfico 4 apresenta o desempenho do Ideb em 2015 no Brasil e por estados, considerando a respectiva meta intermediária - fixada pelo próprio Inep - para esse ano. Os dados revelam que a performance das escolas públicas em nível nacional não foi suficiente para o alcance da respectiva meta, de modo que apenas cinco UFs conseguiram alcançá-la no período (Pernambuco, Amazonas, Ceará, Mato Grosso e Goiás).

É sabido que o desempenho educacional, medido pelo Ideb, está altamente correlacionado com o nível socioeconômico dos alunos e do território, de modo que

15. 0 Ideb é calculado a partir de dois componentes: a taxa de rendimento escolar (aprovação) e as médias de desempenho nos exames aplicados pelo Inep. Os índices de aprovação são obtidos a partir do Censo Escolar, realizado anualmente. 
as regióes mais desenvolvidas do país possuem os melhores indicadores educacionais (Soares e Alves, 2013). No entanto, consideramos que cabe justamente à política educacional fazer maior diferença no caso dos alunos menos favorecidos, que vivem em contextos mais adversos do ponto de vista socioeconômico. A viabilidade dessa equalização de oportunidades educacionais mediante o estabelecimento de padrão mínimo de qualidade do ensino pode ser observada no caso do Ceará, tendo em vista que suas piores condições econômicas e sociais não impediram que seu Ideb alcançasse patamar próximo ao dos estados mais desenvolvidos (Codes e Araújo, 2017; Segatto e Abrucio, 2016).

Outro aspecto que poderia afetar nossa análise consiste na possibilidade de que determinado tipo de rede (estadual ou municipal) pudesse, linearmente, ser mais efetivo em termos de resultados educacionais do que o outro. Todavia não encontramos na literatura validaçáo desse argumento. Ao contrário, estudos revelam que a municipalização das matrículas nas últimas décadas não afetou o desempenho dos alunos (Leme, Paredes e Souza, 2009; Ceneviva, 2012). Em síntese, não foram encontradas evidências empíricas de que o fato de uma escola ser gerida pelo estado ou município afetaria o desempenho dos seus alunos.

\section{GRÁFICO 4}

Ideb: anos finais do ensino fundamental, rede pública - Brasil e UFs (2015)

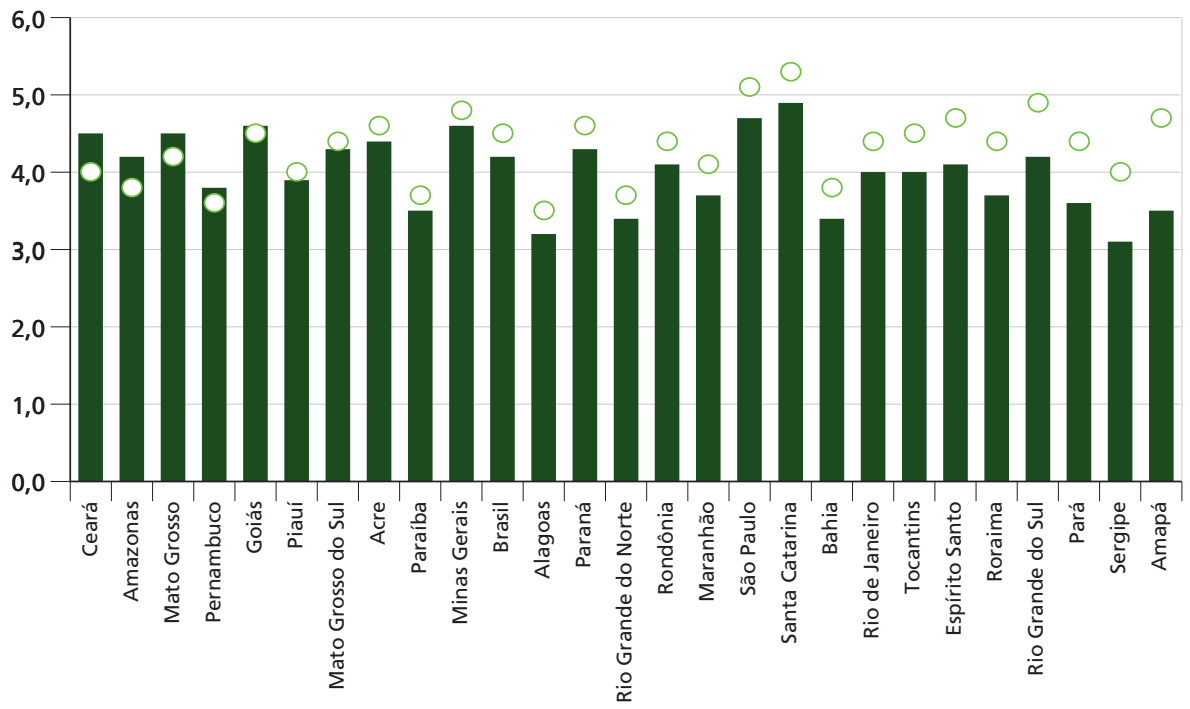

Ideb 2015 Meta Ideb 2015

Fonte: Inep (2015).

Elaboração dos autores.

Diante disso, optamos por analisar o município segundo o respectivo Ideb da rede pública - cuja mensuração considera as escolas do seu território sem distinguir 
se são próprias ou geridas pelo estado. Nossa hipótese é que os municípios de estados que adotam maior grau de coordenação tenham avançado mais rapidamente na escala do Ideb da rede pública no período analisado.

Verificamos tanto o ponto de partida do município - no momento de primeira mensuração do Ideb, em 2005 - quanto seu ponto de chegada, em 2015. O gráfico 5 mostra que os municípios que estáo exatamente sobre a diagonal são aqueles que não tiveram variação do Ideb da rede pública no período. Por sua vez, os que estão abaixo são os que apresentaram piora no indicador. No gráfico, é possível visualizar que a maior parte dos municípios está acima da diagonal e, portanto, apresentou melhoria desde a criação do Ideb.

\section{GRÁFICO 5}

Evolução do Ideb para os anos finais do ensino fundamental: rede pública (2005-2015)

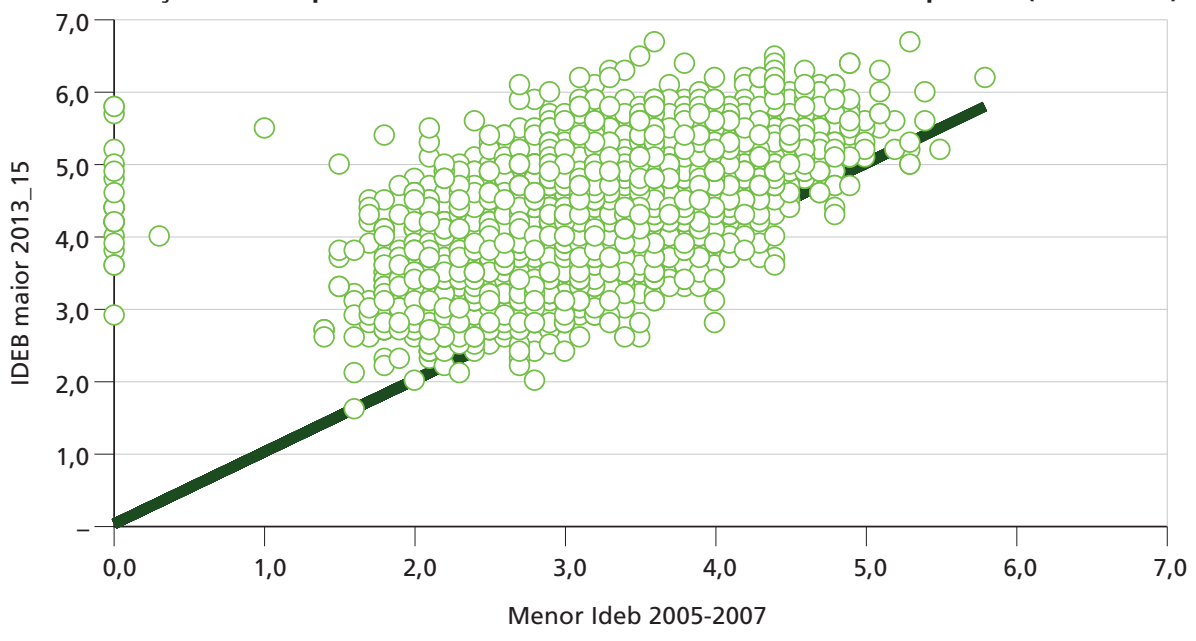

Fonte: Inep (2015).

Elaboração dos autores.

Nota: ${ }^{1}$ Nem todos os municípios apresentam Idebs em todos os anos. Ademais, esse índice não é cumulativo, de modo que 0 bom desempenho em determinado período não garante necessariamente bom desempenho no próximo. Assim, para minimizar o impacto de variações pontuais e abranger o maior número possível de municípios na amostra, optamos por comparar a evolução entre o menor Ideb nas suas duas primeiras mensurações, desde sua criação (2005-2007), com o respectivo maior Ideb nos dois últimos anos disponiveis (2013-2015). Com esses critérios, conseguimos analisar o desempenho de 5.472 municípios.

A distância da diagonal indica o quanto o município melhorou ou piorou no período, de modo que podemos ver um conjunto importante de municípios que apresentou avanços expressivos no Ideb da rede pública. Mas será que esses munícipios, que mais apresentaram ganhos, são os que passaram por experiência de indução/coordenação estadual?

Para continuar a análise, retomamos a tipologia ajustada de Segatto (2015) e Segatto e Abrucio (2016), ilustrada no quadro 1, na forma dos seguintes grupos 
organizados segundo o grau de coordenação estadual junto a seus municípios. Como o foco está na coordenação estadual de redes estaduais e municipais, retiramos dos grupos os estados responsáveis pela quase totalidade da oferta das matrículas nos anos finais do ensino fundamental (acima de 95\% das matrículas estaduais): ${ }^{16}$

- grupo 1 (coord. 1) - políticas independentes (Rondônia, Roraima, Amapá, Pará, Maranhão, Rio Grande do Norte, Rio de Janeiro e Santa Catarina);

- grupo 2 (coord. 2) - açóes conjuntas: (Amazonas, Alagoas, Espírito Santo, São Paulo, Paraná e Rio Grande do Sul);

- grupo 3 (coord. 3) - programas conjuntos (Acre, Tocantins, Sergipe, Piauí, Pernambuco, Bahia, Minas Gerais, Mato Grosso e Goiás); e

- grupo 4 (coord. 4) - coordenaçáo estadual (Ceará, Paraíba e Mato Grosso do Sul).

No gráfico 6, visualizamos a curva de distribuiçáo de cada um dos grupos de municípios dos estados descritos anteriormente, segundo o respectivo Ideb da rede pública no início do período (2005-2007). Verifica-se que os municípios dos grupos 3 e 4 - que apresentam os maiores graus de coordenação estadual na tipologia utilizada - são justamente os que possuíam menor Ideb da rede pública no início da série - cujo epicentro das curvas está mais à esquerda do gráfico. Ademais, os valores do Ideb em cada grupo são relativamente homogêneos - verificado pela largura da curva -, evidenciando desempenhos parecidos dos respectivos municípios.

GRÁFICO 6

Curva de distribuição dos grupos de municípios segundo o grau de coordenação estadual, por Ideb da rede pública (2005-2007)

(Em \%)

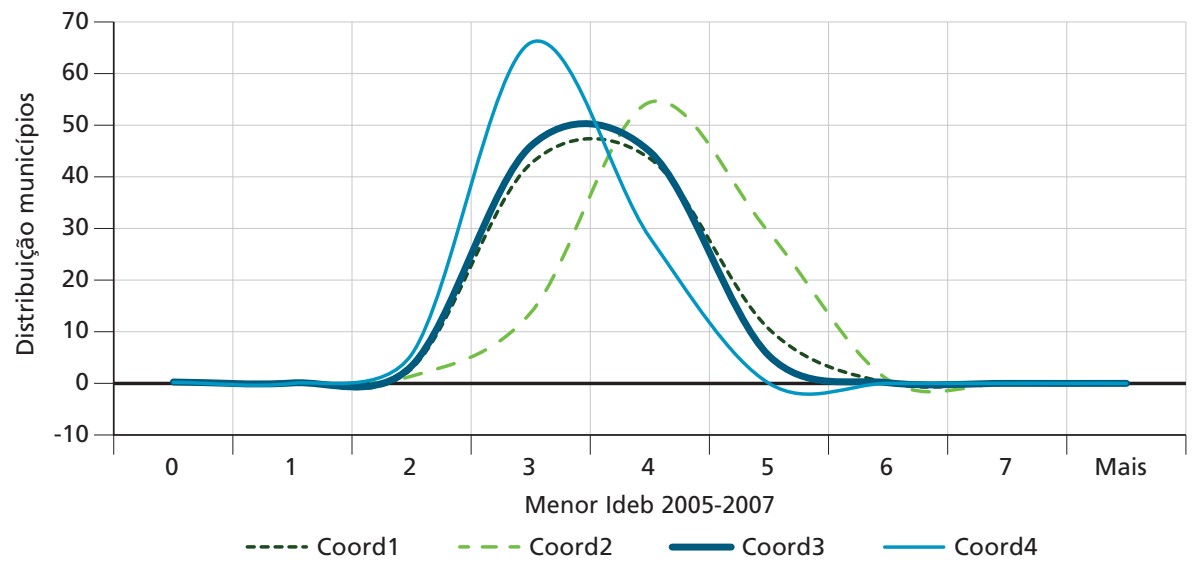

Fonte: Inep (2015).

Elaboração dos autores.

16. Roraima tem 96\%, Amapá tem 95\% e Paraná tem 98\% das matrículas estaduais nos anos finais do ensino fundamental. 
Mas será que, de fato, são os municípios dos grupos 3 e 4 - de menor Ideb no período 2005-2007 e com maior grau de coordenação estadual - os que tiveram maior evolução desse índice no período analisado? Uma forma de investigar esse aspecto é por meio da análise do percentual de avanço proporcional do Ideb municipal no período, objeto do gráfico 7 .

\section{GRÁFICO 7}

Curva de distribuição dos grupos de municípios segundo o grau de coordenação estadual e avanço no Ideb da rede pública (2005-2015)

(Em \%)

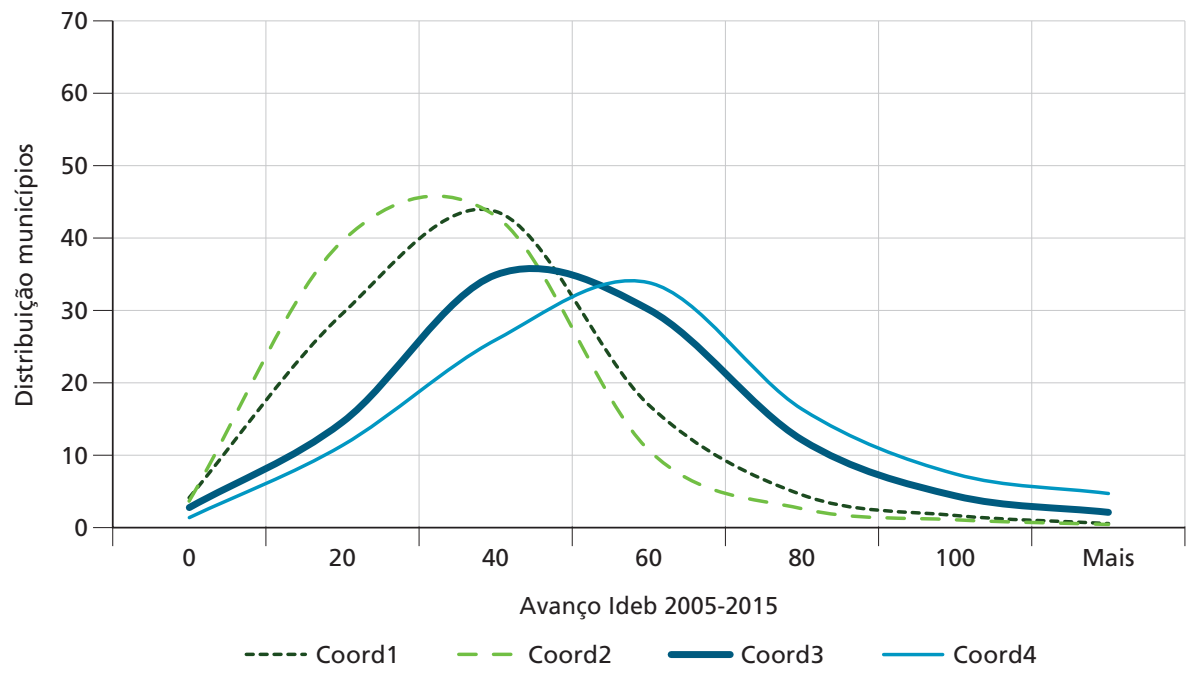

Fonte: Inep (2015).

Elaboração dos autores.

Observa-se que todos os grupos observados no gráfico anterior ficaram internamente mais heterogêneos, quando se analisa seu percentual de avanço no Ideb mostrado no gráfico 7 - apresentando tanto municípios que avançaram muito, quanto municípios que progrediram pouco no Ideb da rede pública. Ademais, na comparação de ambos os gráficos (6 e 7), fica claro que os municípios que pertencem a UFs com maior grau de coordenação estadual (grupos 3 e 4) também foram, em seu conjunto, os que mais avançaram proporcionalmente no Ideb da rede pública no período analisado.

Pode-se argumentar, todavia, que os municípios do grupo 4 são os que apresentavam pior desempenho inicial e que, por isso, possuiriam maior potencial de avanço posterior, tendo-se em vista a lei dos rendimentos decrescentes - quanto pior a situaçáo inicial do Ideb da rede pública do município, maior a possibilidade de ser afetado por fatores que induzam seu aumento - não somente por fatores como coordenação estadual, mas também pela coordenação federal, pela maior 
incidência de recursos disponíveis via Fundeb, pelo aumento de receita própria etc. Para minimizar essa situação, procuramos aproximar as condiçóes do Ideb inicial entre os grupos 1 e 4 (menor e maior coordenação, respectivamente). Retiramos do grupo 1 o estado de Santa Catarina, que, mais desenvolvido, de fato possuía o maior Ideb da rede pública para os anos finais do período 2005-2007 - equivalente a 4,1, segundo o Inep. Com isso, vemos no gráfico 8 que os municípios dos grupos 1 e 4 ficam em situação inicial muito semelhante entre si em termos de desempenho nesse índice, sem alterar substancialmente o avanço no Ideb por parte do grupo 1 - comparando-se o gráfico 9 com o gráfico 7.

\section{GRÁFICO 8}

Curva de distribuição dos grupos de municípios segundo o grau de coordenação estadual, por Ideb da rede pública - sem Santa Catarina (2005-2007) (Em \%)

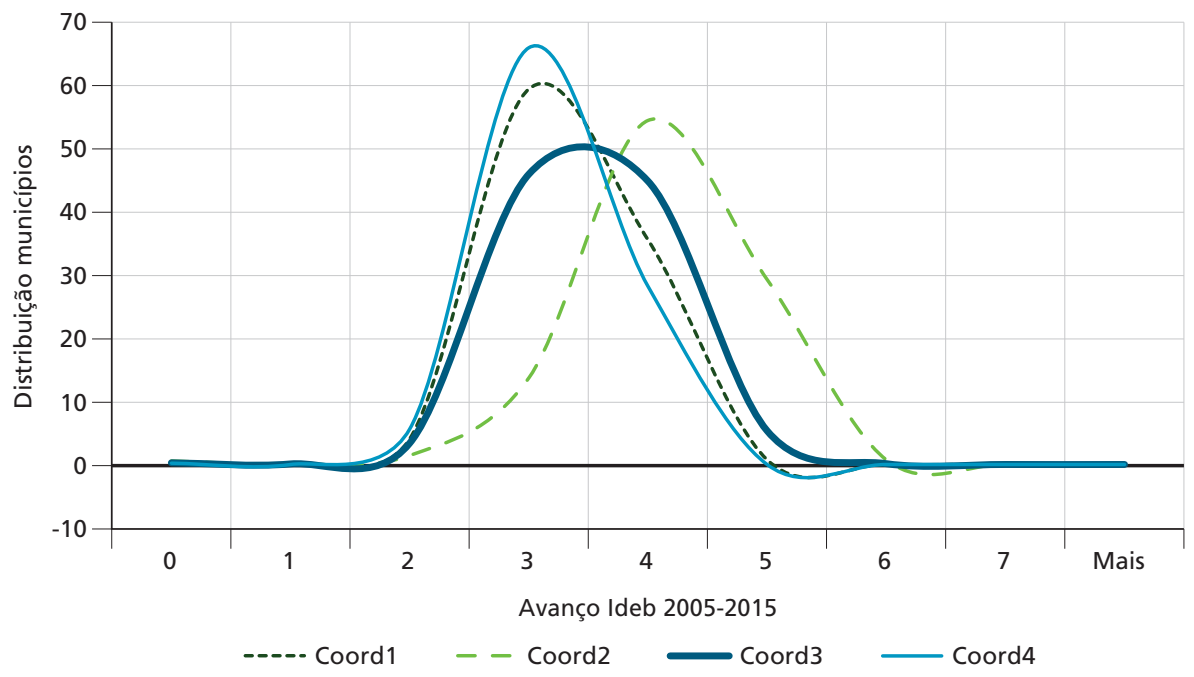

Fonte: Inep (2015).

Elaboração dos autores.

Constatamos, portanto, no gráfico 9, que os municípios de estados com maior grau de coordenação federativa (grupos 3 e 4 ) avançaram mais rapidamente no Ideb no período 2005-2015, embora seus municípios possuíssem índice semelhante na rede pública, no período 2005-2007. Esse achado sinaliza a importância do papel coordenador do governo estadual para avançar nos indicadores educacionais, para além da sua função tradicional de gestor da própria rede.

Cabe explicitar, contudo, que, embora os dados evidenciem associação positiva entre coordenação federativa estadual e desempenho no Ideb, não permitem atribuir, de maneira inequívoca, uma relaçáo de causalidade, de modo que fica 
como sugestão para uma futura pesquisa analisar esse fenômeno, considerando-se a variação de outros fatores que possam impactar no avanço do índice. Ademais, cabe ressaltar que, certamente, o ganho no Ideb da rede pública do conjunto de municípios analisados no período 2005-2015 também deve ter sido afetado pelo aumento da coordenação federativa da União nesse período. Inclusive, como a atuação federal se dirige, em boa parte, a todos os municípios, esse aumento de coordenação pode eventualmente ter alavancado mais aqueles em pior situação. No entanto, a coordenação federal não explica o melhor desempenho relativo por parte dos municípios de estados que praticam a coordenação estadual.

Em suma, os resultados apontam para a relevância da coordenação estadual na melhoria dos resultados educacionais do país. Entretanto, não consideram a distribuição de matrículas entre redes estaduais e municipais para oferta dos anos finais do ensino fundamental. Esse aspecto é explorado no próximo tópico, de modo a identificar os desafios que se impóem a cada perfil de atuação estadual nesse nível de ensino.

\section{GRÁFICO 9}

Curva de distribuição dos grupos de municípios segundo o grau de coordenação estadual e avanço do Ideb da rede pública - sem Santa Catarina (2005-2015) (Em \%)

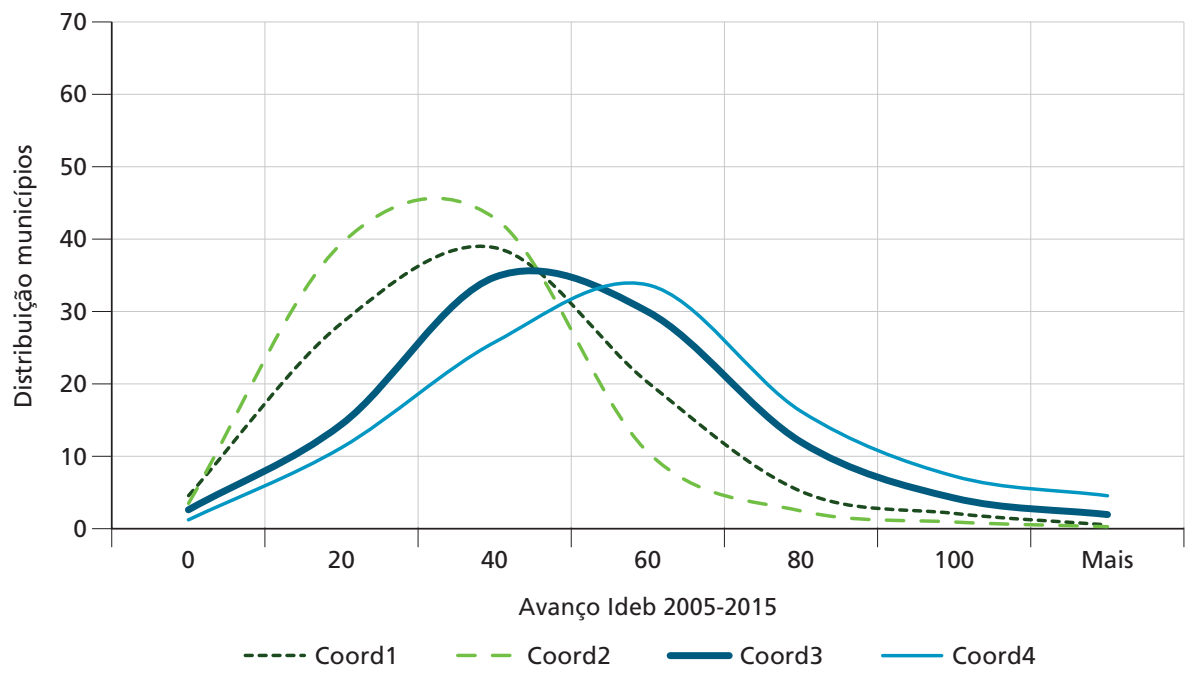

Fonte: Inep (2015).

Elaboração dos autores. 


\section{DIFERENTES PERFIS DE ATUAÇÃO DOS GOVERNOS ESTADUAIS, DIFERENTES DESAFIOS DE COORDENAÇÃO}

Vimos na seção anterior que os anos finais constituem o ciclo do ensino fundamental cujos resultados do Ideb têm ficado mais aquém das respectivas metas (gráfico 5). Também vimos em Segatto (2015) que está em curso uma crescente atuação dos governos estaduais na coordenação da oferta entre ambas as redes no seu território. Constatamos ainda, no período recente, evidências de associaçóes positivas entre a coordenação estadual e o avanço do Ideb dos respectivos municípios (gráficos 6 a 9). Diante disso, propomos, em caráter exploratório, identificar perfis de atuação dos estados na política educacional, levando-se em consideração: i) sua participação direta na provisão de vagas; e $i$ ) sua atuação na coordenação junto aos municípios do território. Sem pretender esgotar a análise em uma tipologia, o que aspiramos com a identificação desses perfis é discutir em que medida a coordenação estadual poderia ser um meio de acelerar a melhoria da qualidade da oferta educacional em seu território.

Assim, partimos da tipologia ajustada de Segatto (2015) e Segatto e Abrucio (2016) (quadro 1), com o objetivo de cotejar as categorias de grau de coordenação com o percentual de matrículas estaduais nos anos finais do ensino fundamental. ${ }^{17}$ Ainda que a autora tenha mensurado os graus de coordenação estadual como um todo, abrangendo todo o ensino fundamental, restringimos a análise do percentual de matrículas aos anos finais do ensino fundamental, pois - como vimos anteriormente - essa é a modalidade mais heterogênea sob a perspectiva da municipalização e, portanto, abriga perfis mais diferenciados de atuação do governo estadual.

Encontramos quatro principais perfis de atuação dos estados nesse nível de ensino.

O primeiro perfil é composto por estados mais "passivos": pouco envolvidos na provisão direta de matrículas nos anos finais do ensino fundamental e que não oferecem apoios substantivos a seus municípios nos anos finais do ensino fundamental. Nesse grupo, a atuação estadual limita-se ao aporte do Fundeb, lembrando que - por determinação constitucional - o estado está obrigado a destinar os recursos estaduais ao fundo. Na prática, esses estados deixam a oferta por conta dos municípios, que não contam com apoio do governo estadual para a gestão de suas redes. O Maranhão exemplifica esse perfil, pois apresenta menor grau de coordenação e oferta pequena de matrículas para os anos finais do ensino fundamental. ${ }^{18}$

17. Estamos cientes de que a pesquisa de Segatto (2015) possui limitação temporal, dado que retratou a relação entre estados e municípios em 2013. A autora até chegou a apurar informações sobre a existência prévia de coordenaçã̃o, mas não o fez para todos os casos. No entanto, como nosso estudo tem caráter exploratório - e dada a ausência de outros levantamentos com a mesma abrangência e especificidade -, entendemos ser cabível cotejar a variável grau de coordenação apurada pela autora com a evolução do Ideb entre 2005 e 2015.

18. Os demais estados do grupo possuem ofertas mais expressivas de matrículas (entre $27 \%$ e $40 \%$ ), mas somente Alagoas e Espírito Santo desenvolvem algum tipo de ação conjunta entre as redes estadual e municipal. 
O segundo perfil é constituído de estados "coordenadores": com baixa oferta de matrículas estaduais, mas com ação mais efetiva de coordenação junto às redes municipais. Promovem uma cooperação institucionalizada entre os entes e adotam mecanismos que redistribuem, em diferentes graus, recursos financeiros, materiais e humanos. O Ceará destaca-se nesse grupo, tendo optado por deixar a oferta majoritariamente a cargo dos municípios, mas prestando apoio efetivo a estes, mediante açôes de avaliação, bonificação e capacitação (Codes e Araújo, 2017). ${ }^{19}$

O terceiro perfil identifica estados "provedores": responsáveis pela maior parte das matrículas dos anos finais do ensino fundamental no seu território, sem, no entanto, apresentarem papel significativo na coordenação federativa junto aos municípios. Roraima, Amapá e Rondônia - estados com legado histórico como ex-territórios federais - destacam-se pela ampla proporção de matrículas estaduais, o que sugere que seus respectivos municípios ainda não conseguiram se estruturar para essa oferta. O Paraná também desponta como estado tipicamente provedor, detendo quase a totalidade da rede nos anos finais do ensino fundamental $(98 \%){ }^{20}$

O último perfil de estados é composto por aqueles mais "ativos": que provêm a maior parte das matrículas nos anos finais e, ainda, possuem uma agenda importante de apoio e indução dos municípios. São estados fortemente envolvidos na oferta dos anos finais do ensino fundamental em seu território - como Acre, Mato Grosso e Mato Grosso do Sul -, nos quais, por essa razão, os municípios podem dedicar-se mais aos anos iniciais do ensino fundamental.

A partir dos perfis delineados, é possível avançar na análise das possibilidades de que melhores resultados no Ideb nas séries finais do ensino fundamental sejam alcançados a partir da ampliação da coordenação estadual. Conquanto o Ceará seja um caso paradigmático, nesse sentido, é necessário levar em consideração sua tradição de cooperação federativa que extrapola a área de educação (Segatto, 2015). Ademais, é um estado com pouca participaçáo na oferta de vagas, o que o torna mais livre para dispor de apoio aos municípios.

Feita essa ressalva, avançamos em alguns diagnósticos. Quatro dos cinco estados que mais avançaram no Ideb no período 2005-2015²1 (Ceará, Pernambuco, Mato

19. Codes e Araújo (2017) avaliam que o regime de colaboração no Ceará se materializa por meio de ações estaduais de avaliação de desempenho, fornecimento de material didático e qualificação dos professores, bem como premiação de resultados - em dinheiro - para as escolas que mais avançaram no Ideb e maior repasse de ICMS para os municípios que mais evoluíram nesse aspecto.

20. o Paraná adota um arranjo interessante de oferta do ensino fundamental entre estados e municípios, em que os primeiros se responsabilizam pela quase totalidade dos anos finais e os segundos, pela quase totalidade dos anos finais. 21. Consideramos que as UFs que mais avançaram em seus resultados educacionais são aquelas que conseguiram ao mesmo tempo: i) estar entre os cinco estados que tiveram maior crescimento percentual no Ideb, no período 2005-2015; e ii) alcançar as metas estabelecidas para o final do período. Assim, foram descartados estados que aumentaram seus Ideb partindo de patamar inicial muito baixo e que - embora tenham apresentado melhoria - ainda figuram entre os piores desempenhos educacionais do Brasil. 
Grosso e Paraíba) possuíam açóes importantes de coordenação da oferta no seu território. Destes cinco, apenas o estado do Amazonas possui um perfil provedor, com oferta da maior parte das vagas nos anos finais do ensino fundamental. Em todo caso, o fato de o Amazonas ter conseguido melhorar o Ideb sem esforço significativo de coordenação estadual sinaliza que, embora importante, há outros caminhos para aprimorar os resultados educacionais para além da coordenação estadual.

Por sua vez, três dos cinco estados que menos avançaram no Ideb no período analisado caracterizam-se como provedores (Rio Grande do Sul, Roraima e Amapá), além de um estado possuir um perfil passivo (Pará). A presença de apenas um estado coordenador nesse grupo (Sergipe) é outro indício da importância da coordenação estadual para esse fim. Aliás, chama atenção o contraste entre Ceará e Sergipe, dois estados da mesma regiāo, com indicadores socioeconômicos parecidos, e que partiram de patamares muito próximos de desempenho no Ideb em 2005. Diferentemente do Ceará, Sergipe teve o pior resultado nesse índice em 2015. Uma possível explicação do desempenho tão diferente de estados com situaçôes semelhantes parece estar na efetividade das açóes de coordenação, que, de acordo com Segatto (2015), são mais amplas e estruturadas no Ceará, sugerindo que nem toda coordenação, necessariamente, está associada a avanços nos resultados educacionais. Ademais, embora em ambos os casos haja maioria de matrículas municipais, no caso de Sergipe, o Estado responde por quase $40 \%$ das matrículas, sugerindo-se que - tal como no caso do Amazonas - a coordenação estadual possa ter mais dificuldade de operar quanto mais heterogêneo for o arranjo institucional para oferta do ensino fundamental em um mesmo território.

\section{CONSIDERAÇÕES FINAIS}

A atuação dos governos estaduais na educação básica passou por uma grande mudança nos últimos vinte anos. Se, desde o Império, as províncias/estados figuravam como grandes responsáveis pelo ensino fundamental - com uma atuação secundária dos municípios nesse nível de ensino - a partir da CF/1988 esse papel passou a ser formalmente dividido com os entes municipais, que terminaram por assumir, nos dias atuais, a centralidade na sua oferta.

Contudo, o escopo de atuação desses entes só mudou, efetivamente, com o avanço da descentralizaçáo do ensino fundamental na segunda metade da década de 1990, mediante a qual todos os entes estaduais enfrentaram, em alguma medida, um processo de municipalização das matrículas, ainda que tenham permanecido como principais financiadores da educaçáo básica por meio do Fundef/Fundeb. Ao mesmo tempo, a LDB de 1996 atribuiu aos estados a função redistributiva e supletiva em relação aos sistemas de ensino do seu território, responsabilizando-os também pela redução das disparidades de acesso e garantia de padrão mínimo de qualidade de ensino. 
O fenômeno da dualidade de redes caracterizado pela oferta concomitante do ensino fundamental por estados e municípios trouxe desafios, no sentido de evitar lacunas no processo educacional das crianças que, via de regra, transitam entre ambas as redes, ao seguir o percurso do ensino obrigatório. Por essa razão, a coordenação das redes estaduais e municipais vem adquirindo maior importância para a garantia do acesso ao direito à educação de qualidade em todo o território nacional.

Consideramos que, sobretudo nos casos de maior municipalização das matrículas do ensino fundamental, o governo estadual deve reforçar suas açóes de coordenaçáo como forma de evitar sobreposiçóes, lacunas, propiciar a equalização das oportunidades educacionais e um padrão mínimo de qualidade. Nesse sentido verificamos que, embora a coordenação estadual não seja condição suficiente para acelerar o avanço no Ideb, esta parece fazer maior diferença em duas situaçóes cumulativas nos estados: $i$ ) em que tenha havido um amplo processo de municipalização das matrículas; e ii) que apresentem perfil socioeconômico vulnerável, os quais geralmente possuem Ideb mais baixo. Nesse caso, a coordenação estadual atuaria na compensação das dificuldades de gestão dos municípios com menores capacidades estatais.

Identificamos ainda diferentes perfis de atuação estadual nos anos finais do ensino fundamental, tendo-se em vista sua dupla função. Enquanto alguns atuam, principalmente, como gestores de rede, outros apostam na coordenação dos sistemas municipais. Há ainda estados que desempenham duplo papel, gerindo uma rede significativa e, ao mesmo tempo, buscando articular sua oferta com a das escolas municipais. A constatação de que quatro dos cinco estados que mais avançaram no Ideb no período analisado possuem representantes com algum perfil de coordenação indica que coordenar é importante, mas não suficiente; por isso, cabe atentar para o escopo e a abrangência das açôes envolvidas nesse processo.

Por sua vez, estão em condição crítica os estados mais passivos, cujo perfil é de baixa oferta própria e baixa coordenação federativa, nos quais os municípios são responsáveis pela maior parte das matrículas, sem contar com apoio do governo estadual para tanto. Alguns desses estados (Rio Grande do Norte, Pará, Maranhão e Alagoas), inclusive, estão regionalmente próximos e, tal como o estado do Ceará, possuem as condiçóes socioeconômicas e de desempenho, no Ideb, necessárias para que se beneficiem da adoção de estratégias de coordenação estadual.

A conclusão, em suma, é que diferentes perfis de atuação dos estados na política educacional parecem conduzir a bons resultados no Ideb (Ceará e Amazonas, por exemplo). No entanto, a constatação de maiores avanços por parte dos estados que adotam açôes de coordenação - assim como os resultados pouco expressivos daqueles com perfil passivo nesse aspecto -mostra que essa atitude faz diferença em determinadas situaçóes. Fica como sugestão de possíveis desdobramentos da 
pesquisa aprofundar, em uma tipologia, os perfis de atuaçáo dos governos estaduais, de modo a contextualizar os desafios de coordenação federativa que se impóem para cada contexto.

Ao refletir sobre o duplo papel do estado na gestão do ensino fundamental, esta pesquisa destaca a relevância da atuação dos governos estaduais para alavancar os resultados educacionais do país. Para além do financiamento do Fundeb ou de gestáo da própria rede, argumentamos que, em muitos casos, faz diferença investir em mecanismos de coordenação estaduais. Esse, inclusive, é um aspecto que deve ser considerado no âmbito dos instrumentos de coordenação federativa por parte da União, de modo a, por exemplo, contemplar o papel coordenador dos governos estaduais no âmbito dos programas federais operados pelo MEC - em especial nas açôes dirigidas às regiôes Norte e Nordeste, que possuem maior municipalização das matrículas, piores condiçóes socioeconômicas e resultados educacionais.

\section{REFERÊNCIAS}

ABRUCIO, F.L. A dinâmica federativa da educação brasileira: diagnóstico e propostas de aperfeiçoamento. In: PORTELA, R.; SANTANA, W. (Orgs.). Educaçáo e federalismo no Brasil: combater desigualdades, garantir diversidade. Brasília: Unesco, 2010. 299 p.

ARRETCHE, M.; FUSARO, E.; GOMES, S. Democracia, políticas sociais e pobreza no Brasil. In: ENCONTRO DA ASSOCIAÇÃO BRASILEIRA DE CIÊNCIA POLÍTICA, 8., 2012, Gramado, Rio Grande do Sul. Anais... Gramado, 2012.

ARRETCHE M.; VASQUEZ, D.; GOMES, S. As relaçóes verticais na Federação: explorando o problema da descentralização. In: ARRETCHE, M. (Org.). Democracia, federalismo e centralizaçáo no Brasil. Rio de Janeiro: FGV Editora; Editora Fiocruz, 2012. p. 145-202.

BRASIL. Ministério da Educação. Secretaria de Articulação com os Sistemas de Ensino. O Sistema Nacional de Educaçáo: diversos olhares 80 anos após o manifesto/Ministério da Educação. Brasília: Sase/MEC, 2014. 220 p.

CASTRO, J. A. Evolução e desigualdade na educação brasileira. Educaçáo e Sociedade, Campinas, v. 30, n. 108, p. 673-697, out. 2009.

. Dilemas para o financiamento da educação. In: BRASIL. Ministério da Educação. O Sistema Nacional de Educação: diversos olhares 80 anos após o manifesto. Brasília: Sase/MEC, 2014.

CENEVIVA, R. O nível de governo importa para a qualidade da política pública? A municipalização da educação fundamental no Brasil. In: SEMINÁRIO DISCENTE PÓS-GRADUAÇÃO EM CIÊNCIA POLÍTICA DA USP, 2., 2012, São Paulo. Anais... São Paulo, 2012. 
CODES, A.; ARAÚJO, H. Lições de experiências exitosas para melhorar a educação em regióes com baixos índices de desenvolvimento. Brasília: Ipea, 2017. Disponível em: <https://is.gd/iC47PI>.

CURY, C. R. J. Sistema Nacional de Educação: desafio para uma educação igualitária e federativa. Educaçáo e Sociedade, Campinas, v. 29, n. 105, p. 1187-1209, dez. 2008.

FILIPPIM, E. S.; ABRUCIO, F. L. Quando descentralizar é concentrar poder: o papel do governo estadual na experiência catarinense. Revista de Administraçáo Contemporânea, Curitiba, v. 14, n. 2, art. 2, p. 212-228, mar./abr. 2010.

FRACALANZA, P. S. A gestáo do ensino fundamental pelo governo do estado de São Paulo: uma análise do financiamento e dos indicadores sociais de educação (1980-1993). Educaçáo e Sociedade, ano 20, n. 69, p. 92-118, dez. 1999.

GOMES, S. Políticas nacionais e implementação subnacional: uma revisão da descentralização pós-Fundef. Revista de Ciências Sociais, v. 52, n. 3, p. 659690, 2009.

INEP - INSTITUTO NACIONAL DE ESTUDOS E PESQUISAS EDUCACIONAIS ANÍSIO TEIXEIRA. Sinopses estatísticas da educação básica. Brasília: Inep, 2015. Disponível em: <https://is.gd/N8k14P>.

Resumo técnico: resultados do Ideb 2005-2015. Brasília: Inep, [s. d.].

LEME, M. C.; PAREDES, R.; SOUZA, A. P. A municipalização do ensino fundamental e seu impacto sobre a proficiência no Brasil. In: VELOSO, F. et al. (Eds.). Educaçáo básica no Brasil: construindo o país do futuro. Rio de Janeiro: Campus-Elsevier, 2009.

SANFELICE, José L. A política educacional do estado de São Paulo: apontamentos. Nuances: estudos sobre educação, ano XVII, v. 17, n. 18, p. 146-159, jan./ dez. 2010.

SEGATTO, C. I. O papel dos governos estaduais nas políticas municipais de educaçáo: uma análise dos modelos de cooperação intergovernamental. 2015. Tese (Doutorado) - Escola de Administração de Empresas de São Paulo, Fundação Getulio Vargas, São Paulo, 2015.

SEGATTO, C. I. Policy diffusion in subnational governments: State local relationships in the Brazilian education policy. Regional and Federal Studies, v. 28, n. 1, p. 79-100, 2017.

SEGATTO, C. I.; ABRUCIO, F. L. A cooperação em uma federação heterogênea: o regime de colaboração na educação em seis estados brasileiros. Revista Brasileira de Educaçáo, v. 21, n. 65, p. 411-429, 2016. 
SOARES, J. F.; ALVES, M. Efeitos de escolas e municípios na qualidade do ensino fundamental. Cadernos de Pesquisa, v. 43, n. 149, p. 492-517, 2013.

SOUSA, S. Z.; ARCAS, P. H. Implicaçôes da avaliação em larga escala no currículo: revelaçóes de escolas estaduais de São Paulo. Educaçáo: teoria e prática, v. 20, n. 35, p. 181-199, jul./dez. 2010.

SOUZA, C. Coordenação de políticas públicas. Brasília: Enap, 2018.

TORRES, H. G. et al. Educação na periferia de São Paulo: ou como pensar as desigualdades educacionais? A cidade contra a escola? Segregação urbana e desigualdades educacionais em grandes cidades da América Latina. In: NEIGHBORHOOD EFFECTS, EDUCATIONAL ACHIEVEMENTS AND CHALLENGES FOR SOCIAL POLICIES, 2006, Rio de Janeiro. Anais... Rio de Janeiro, ago. 2006.

VAZQUEZ, D. A. Mecanismos institucionais de regulação federal e seus resultados nas políticas de educação e saúde. Dados: revista de ciências sociais, Rio de Janeiro, v. 57, n. 4, p. 969-1005, 2014. 